\title{
Penyuluhan dan Pendampingan Penataan Lingkungan Pada Permukiman Kumuh Di Kelurahan Bontorannu, Kecamatan Mariso, Kota Makassar
}

\author{
Mimi Arifin*, A.Yudhono, S.Trisutomo, S.Wunas, Y.Jinca, Arifuddin Akil, A.R.Rasyid, I.Latief, \\ M.Ali, F.Azmy, Y.K.Dewi, W.W.Osman, S.A.Ekawati, S.Wahyuni, L.M.Asfan, G.Lakatupa \\ Departemen Perencanaan Wilayah dan Kota, Fakultas Teknik Universitas Hasanuddin \\ mimiarifin@unhas.ac.id*
}

\begin{abstract}
Abstrak
Permukiman padat di pinggiran Kanal Jongaya Kelurahan Bontorannu adalah salah satu penyebab tercemarnya lingkungan Pantai Losari sebagai landmark Kota Makassar. Penumpukan sampah di sepanjang kanal makin menguatkan perilaku masyarakat membuang sampah di kanal. Kawasan Kelurahan Bontorannu memiliki beberapa potensi yang dapat dijadikan faktor pendukung dalam upaya revitalisasi yakni kanal yang dapat dimanfaatkan sebagai transportasi air karena kanal Jongaya terhubung ke Pantai Losari dan pulau - pulau disekitarnya. Sebagai permukiman nelayan yang berada di perkotaan serta di kawasan strategis koridor pesisir yang memiliki nilai lebih sebagai Pusat Bisnis dan Pariwisata Terpadu. (RT/RW Kota Makassar 2015-2034) tentu menjadi daya tarik. Tujuan pengabdian masyarakat untuk 1) Mengidentifikasi karakteristik prasarana permukiman masyarakat dan preferensi masyarakat terhadap kondisi permukiman tepian Kanal Jongaya di Kelurahan Bontorannu Kecamatan Mariso Kota Makassar. 2) Menyusun arahan penataan lingkungan pada permukiman kumuh di Kelurahan Bontorannu Kecamatan Mariso Kota Makassar berbasis masyarakat. Metode yang digunakan yaitu focus group discussion (FGD) untuk mendapatkan masukan akan kebutuhan dan masalah di lingkungan masyarakat serta pemberian stimulus yang tepat kepada masyarakat sehingga persepsi dan usulan penanganan masalah terhadap lingkungan dan kondisi permukiman sesuai dengan yang diharapkan. Arahan penataan yang direkomendasikan dalam mengatasi kondisi permukiman antara lain: pengadaan lampu jalan, penambahan tempat sampah di setiap lorong dan tepi kanal, pembebasan lahan di RW 1, RW 2, RW 3, dan RW 4 untuk membuka akses jalan, menyediakan lahan parkir bagi wisatawan yang datang berkunjung, serta keinginan masyarakat untuk berjualan kuliner, cendramata, dan pembuatan spot foto untuk menarik kunjungan wisatawan sehingga dapat meningkatkan perekonomian masyarakat.
\end{abstract}

Kata Kunci: penataan permukiman; prasarana; berbasis masyarakat; sampah; nelayan.

\begin{abstract}
Dense settlements on the outskirts of Jongaya Canal, Bontorannu Urban Village, are one of the causes of the pollution of the Losari beach environment as a landmark in Makassar. The accumulation of rubbish along the canal further strengthens people's behavior in disposing garbage in the canal. The Bontorannu urban area has several potentials that can be used as supporting factors in revitalization efforts, namely canals that can be used as water transportation because the Jongaya canal can be connected to Losari Beach and surrounding islands. As a fisherman settlements located in urban area and also in a strategic area of a coastal corridor that has more value as an Integrated Business and Tourism Center (Makassar City RTRW 2015-2034), it certainly becomes an attraction. The purpose of community dedication is to 1) Identify the characteristics of the infrastructure of community settlements and the community's preference for the condition of the edge of the Jongaya Canal settlement in the Bontorannu Village, Mariso District, Makassar City. 2) Arranging the direction of environmental structuring in slums in Bontorannu Sub-district Mariso District Makassar City based on community. The method used is a focus group discussion (FGD) to get input on the needs and problems in their environment as well as providing appropriate stimulus to the community so that community perceptions and proposals for handling problems with the environment and settlement conditions are as expected. Recommended directions for dealing with settlement conditions include: procurement of street lights, addition of trash bins in each corridor and canal edge, land acquisition in $R W 1, R W 2, R W 3$, and $R W 4$ to open road access, provide parking area for tourists who come to visit, as well as the desire of the community to sell culinary, souvenirs, and making photo spots to attract tourists to increase the community economy.
\end{abstract}

Keywords: settlement arrangement; infrastructure; community-based; rubbish; fisherman. 


\section{Pendahuluan}

Permukiman sekitar Kanal Jongaya khususnya pada Kelurahan Bontorannu terus mengalami kemunduran vitalitas ekonomi, lingkungan dan sosial. Pembangunan permukiman yang tidak terkendali menyebabkan kepadatan bangunan yang tinggi dan tidak terarah baik dari sisi koefisien kepadatan bangunan, tata bangunan maupun kebersihan lingkungan. Hal ini menyebabkan makin menurunnya kualitas lingkungan perumahan serta dapat menimbulkan peningkatan tingkat kriminalitas.

Kawasan permukiman perkotaan yang berada di pinggiran Kanal Jongaya sebagai salah satu penyebab tercemarnya lingkungan seperti penumpukan sampah yang tinggi serta kualitas air yang buruk yang berdampak pada tercemarnya Pantai Losari sebagai salah-satu landmark Kota Makassar. Kondisi lingkungan bantaran Kanal Jongaya khusunya pada Kelurahan Bontorannu mengalami degradasi seperti masalah lingkungan kanal dan permukiman yang kurang layak huni.

Dalam rangka terciptanya kawasan permukiman yang bersih dan tertata, maka diperlukan penataan prasaranan permukiman di seluruh kawasan dalam batas wilayah administrasi sehingga sesuai dengan rencana yang tertuang. Pengelolaan dan pengalokasian penggunaan lahan dalam hubungannya dengan penataan/perencanaan struktur ruang kota yang diharapkan mampu mewadahi segala aktivitas yang dilakukan warga kota dan mengurangi kesenjangan pembangunan antar wilayah sehingga pola struktur tata ruang mampu menjadi "entry point" bagi akselerasi pembangunan kota. Masyarakat berperan penting dalam pembangunan dan hal ini harus ditumbuhkembangkan. Salah satu cara yang dapat dilakukan adalah melalui sosialisasi dan pendampingan penataan lingkungan permukiman yang masalah dan solusinya berasal dari masyarakat.

\section{Latar Belakang Teori}

Kawasan permukiman perkotaan yang berada di pinggiran Kanal Jongaya sebagai salah satu penyebab tercemarnya lingkungan abiotik seperti penumpukan sampah yang tinggi serta kualitas air yang buruk yang berdampak pada tercemarnya Pantai Losari sebagai salah satu landmark Kota Makassar. Karakteristik lingkungan bantaran Kanal Jongaya mengalami degradasi seperti masalah lingkungan kanal dan permukiman yang kurang layak huni.

Selain itu Kanal Jongaya memiliki berbagai permasalahan ekonomi, lingkungan dan sosial yang dapat mengancam potensi kawasan. Dari segi ekonomi, permasalahan kawasan ini berupa kurangnya jumlah usaha, sedikitnya lapangan pekerjaan, dan penurunan produktivitas ekonomi. Dari segi lingkungan, permasalahan kawasan ini berupa permukiman di sempadan kanal, kerusakan ekologi kanal, kerusakan fasilitas kenyamanan kawasan, dan prasarana sarana yang kurang memadai. Dari segi sosial, permasalahan kawasan ini berupa urbanisasi tinggi, kriminalitas tinggi, pendidikan rendah, dan tingkat kesehatan rendah.

Garis sempadan sungai merupakan jarak bebas atau batas wilayah sungai yang tidak boleh dimanfaatkan untuk lahan budi daya atau untuk didirikan bangunan (Permen PU No 40 Tahun 2007). Akan tetapi, sempadan Kanal Jongaya di Kota Makassar dimanfaatkan untuk membangun bangunan permukiman.

Menurut Peraturan Menteri Pekerjaan Umum Nomor 63 Tahun 1993 tentang Garis Sempadan Sungai, Daerah Manfaat Sungai, Daerah Penguasaan Sungai dan Bekas Sungai dikatakan bahwa 
sungai adalah tempat-tempat dan wadah-wadah serta jaringan pengaliran air mulai dari mata air sampai muara dengan dibatasi kanan dan kirinya sepanjang pengalirannya oleh garis sempadan. Garis sempadan sungai adalah garis batas luar pengamanan sungai. Garis sempadan sungai bertanggul di dalam kawasan perkotaan ditetapkan sekurang-kurangnya 3 (tiga) meter di sebelah luar sepanjang kaki tanggul. Sedangkan bantaran sungai adalah lahan pada kedua sisi sepanjang sungai dihitung dari tepi sungai sampai dengan kaki tanggung sebelah dalam.

Kawasan Kanal Jongaya memiliki beberapa potensi yang dapat dijadikan faktor pendukung dalam upaya revitalisasi yakni kanal yang dapat dimanfaatkan sebagai transportasi air karena Kanal Jongaya dapat terhubung ke Pantai Losari dan pulau-pulau disekitarnya, permukiman nelayan sebagai daya tarik kawasan dan letak kawasan yang berada di kawasan strategis koridor pesisir (RTRW Kota Makassar 2015-2034) memiliki nilai lebih sebagai Pusat Bisnis dan Pariwisata Terpadu.

Apabila Kanal Jongaya terus mengalami kemunduran vitalitas ekonomi, lingkungan dan sosial maka pada kawasan ini akan mengalami pertambahan permukiman di sempadan kanal, hilangnya mata pencaharian masyarakat sebagai nelayan karena kurang adanya prasarana yang mendukung mata pencaharian, pembangunan permukiman yang tidak terkendali menyebabkan kepadatan bangunan yang tinggi sehingga jalan lokal semakin sempit, bertambahnya jumlah permukiman kumuh, dan peningkatan tingkat kriminalitas.

\section{Metode}

\subsection{Sasaran}

Sasaran target peserta kegiatan pengabdian masyarakat adalah seluruh masyarakat di tepian Kanal Jongaya, Kelurahan Bontoranu, Kecamatan Mariso.

\subsection{Pelaksanaan Kegiatan}

a. Langkah-Langkah Pelaksanaan dan Solusi

Langkah pelaksanaan terdiri dari 1) survei awal, 2) desain, 3) sosialisasi, 4) pelaksanaan, dan 5) evaluasi (Tabel 4.1).

Adapun solusi permasalahan mitra yang telah disepakati dengan melalui sosialisasi kepada masyarakat tepian Kanal Jongaya mengenai masalah pada lokasi dan solusi yang ditawarkan kepada mereka untuk meningkatkan penataan kawasan permukiman tepian Kanal Jongaya berbasis masyarakat.

Tabel 1. Kerangka Tahapan Pelaksanaan

\begin{tabular}{lll}
\hline \multicolumn{1}{c}{ Tahapan kegiatan } & \multicolumn{1}{c}{ Keterangan } \\
\hline Survei Awal & 1. Identifikasi karakteristik lokasi \\
& 2. Identifikasi minat dan tingkat pemahaman masyarakat tepian \\
& Kanal Jongaya tentang penataan kawasan permukiman \\
Konsep & 1. Pengusul membuat tahapan konsep penataan kawasan \\
& permukiman di tepian kanal Jongaya \\
Sosialisasi & 1. Presentasi materi \\
Pelaksanaan & 2. Pengarahan/pendampingan tentang konsep arahan \\
& 1. Tindak-lanjut penerapan arahan konsep \\
& 2. Pendampingan kepada kelompok masyarakat \\
\hline
\end{tabular}




\begin{tabular}{ll}
\hline Tahapan kegiatan & Keterangan \\
\hline Evaluasi & Pemanfaatan hasil pelaksanaan \\
\hline
\end{tabular}

b. Lokasi Kegiatan

Lokasi kegiatan difokuskan pada kawasan tepian Kanal Jongaya dengan dasar pertimbangan, 1) segi ekonomi, 2) segi lingkungan, dan 3) segi sosial.

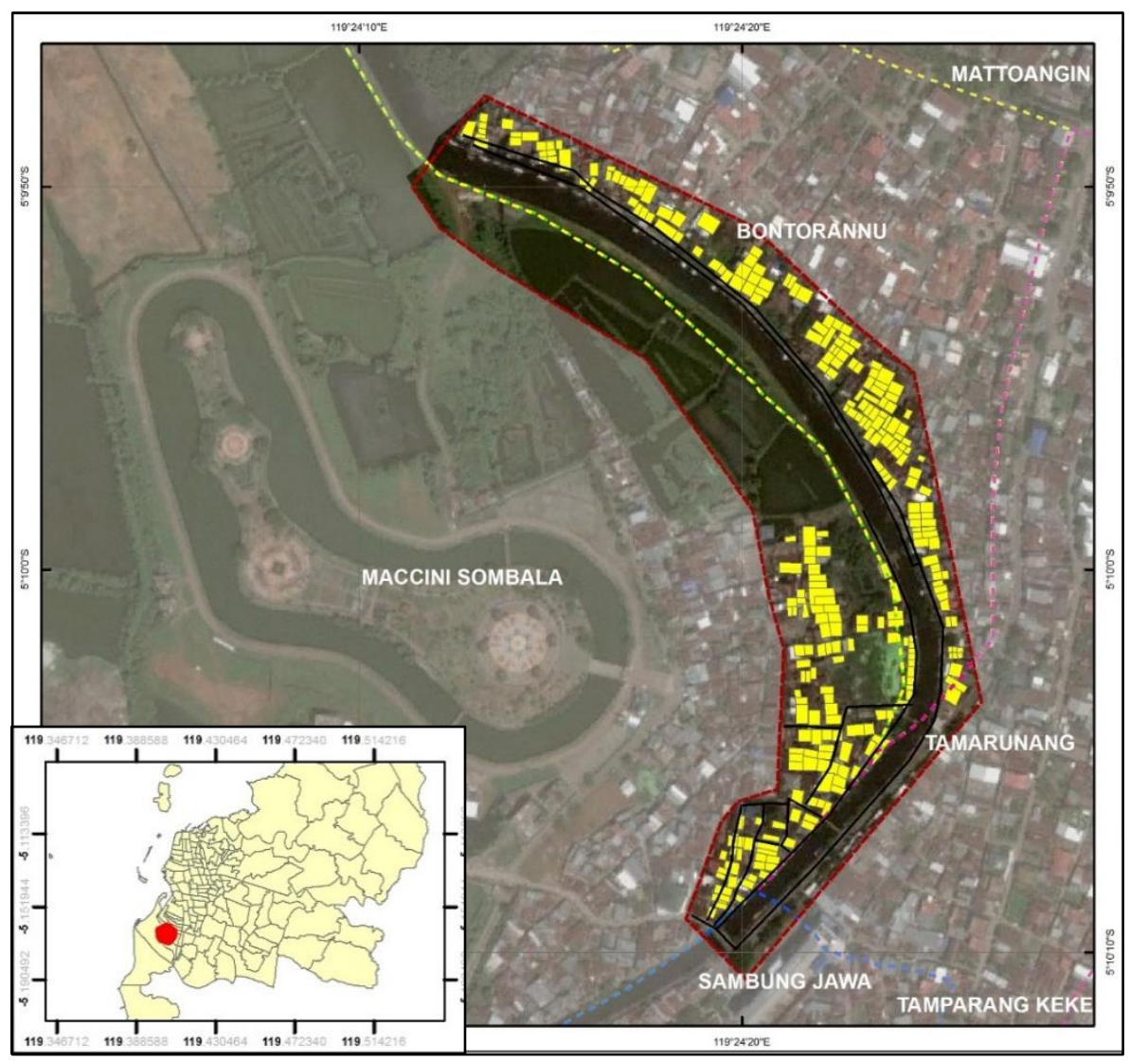

Gambar 1. Ilustrasi lokasi penelitian

c. Bentuk Kegiatan dan Pendekatan Kepada Masyarakat

Bentuk kegiatan dalam pelaksanaan pengabdian masyarakat ini adalah:

1. Presentasi/ ceramah mengenai Penyuluhan dan Pendampingan Penataan Lingkungan Pada Permukiman Kumuh Di Kelurahan Bontorannu, Kecamatan Mariso, Kota Makassar.

2. Pengarahan dan pendampingan langsung mengenai penataan kawasan permukiman tepian Kanal Jongaya berbasis masyarakat.

3. Pengarahan/ penjelasan dan pendampingan langsung cara menata kawasan permukiman berbasis masyarakat. 


\section{Target Capaian}

\subsection{Solusi yang Ditawarkan dan Luarannya}

Terdapat 3 (tiga) permasalahan prioritas dalam usulan kegiatan pengabdian masyarakat ini dan telah tersusun dalam tahapan pelaksanaannya dengan harapan dapat tercapai target luaran (Tabel 2).

Tabel 2. Kerangka Pemecahan Masalah

\begin{tabular}{|c|c|c|}
\hline Permasalahan & $\begin{array}{c}\text { Pemecahan } \\
\text { Masalah } \\
\end{array}$ & Target Luaran \\
\hline $\begin{array}{l}\text { Segi sosial, permasalahan } \\
\text { kawasan ini berupa } \\
\text { urbanisasi tinggi, } \\
\text { kriminalitas tinggi, } \\
\text { pendidikan rendah, dan } \\
\text { tingkat kesehatan rendah }\end{array}$ & $\begin{array}{l}\text { Memupuk rasa } \\
\text { kebersamaan dan } \\
\text { percaya diri } \\
\text { masyarakat atas } \\
\text { kemampuan dalam } \\
\text { mengatasi masalah } \\
\text { secara bersama-sama } \\
\text { Pengarahan: } \\
\text { Memberikan/ } \\
\text { pendampingan peran } \\
\text { serta masyarakat } \\
\text { dalam penataan } \\
\text { kawasan } \\
\text { permukiman tepian } \\
\text { Kanal Jongaya } \\
\text { Kelurahan } \\
\text { Bontorannu } \\
\text { Peningkatan } \\
\text { ketrampilan } \\
\text { (Pendidikan non } \\
\text { formal) yang mampu } \\
\text { mendukung } \\
\text { kesempatan } \\
\text { berwirausaha } \\
\text { Sosialisasi } \\
\text { pentingnya hidup } \\
\text { sehat }\end{array}$ & $\begin{array}{l}\text { 1.Terealisasi cara untuk } \\
\text { menciptakan } \\
\text { lingkungan } \\
\text { permukiman yang } \\
\text { nyaman dan layak huni. } \\
\text { 2.Peta konsep penataan } \\
\text { prasarana kawasan } \\
\text { permukiman } \\
\text { 3.Penyedian ruang } \\
\text { interaksi sosial yang } \\
\text { dapat berfungsi sebagai } \\
\text { tempat pelatihan dan } \\
\text { olah raga } \\
\text { 4.Penyediaan ruang } \\
\text { ekonomi }\end{array}$ \\
\hline $\begin{array}{l}\text { Segi lingkungan, } \\
\text { permasalahan kawasan ini } \\
\text { Penumpukan sampah } \\
\text { produk masyarakat local } \\
\text { dan sampah kiriman } \\
\text { Arah rumah yang } \\
\text { membelakangi kanal } \\
\text { sempadan kanal, }\end{array}$ & $\begin{array}{l}\text { Focus discussion } \\
\text { group dalam } \\
\text { mendapatkan data } \\
\text { masyarakat } \\
\text { kebutuhan dan } \\
\text { masalah serta } \\
\text { solusinya } \\
\text { Sosialisasi: }\end{array}$ & $\begin{array}{l}\text { 1.Arahan Penataan } \\
\text { Pedestrian kawasan } \\
\text { permukiman di tepian } \\
\text { kanal Jongaya } \\
\text { Kelurahan Bontorannu } \\
\text { berbasis masyarakat. } \\
\text { 2.Arahan perbaikan } \\
\text { jembatan berbasis }\end{array}$ \\
\hline
\end{tabular}




\begin{tabular}{|c|c|c|}
\hline $\begin{array}{l}\text { Jembatan yang rendah } \\
\text { kurang mendukung } \\
\text { kenyamanan transportasi } \\
\text { sepanjang kanal, dan } \\
\text { prasarana pedestrian yang } \\
\text { kurang memadai }\end{array}$ & $\begin{array}{l}\text { preferensi kepada } \\
\text { masyarakat akan } \\
\text { kemanfaatan dalam } \\
\text { ikut berpartisipasi } \\
\text { membangun } \\
\text { permukiman yang } \\
\text { lsayak, aman dan } \\
\text { nyaman }\end{array}$ & $\begin{array}{l}\text { masyarakat } \\
\text { 3.Pembuatan tempat } \\
\text { sampah } \\
\text { 4.Saran ke pemerintah } \\
\text { memotivasi swasta } \\
\text { membantu pengadaan } \\
\text { perahu pengangkut } \\
\text { sampah }\end{array}$ \\
\hline $\begin{array}{l}\text { Segi ekonomi, permasalahan } \\
\text { kawasan ini berupa } \\
\text { kurangnya jumlah usaha, } \\
\text { sedikitnya lapangan } \\
\text { pekerjaan, dan penurunan } \\
\text { produktivitas ekonomi } \\
\text { nelayan. } \\
\text { Konflik lahan sekitar kanal } \\
\text { RW 4, } 32 \text { dan RW1 }\end{array}$ & $\begin{array}{l}\text { Pengembangan } \\
\text { sumber daya } \\
\text { manusia dalam } \\
\text { bentuk pelatihan } \\
\text { pengelolaan industri } \\
\text { rumah tangga } \\
\text { Peningkatan } \\
\text { diversifikasi hasil } \\
\text { olah perikanan } \\
\text { tangkap yang } \\
\text { mendukung kegiatan } \\
\text { pariwisata } \\
\text { Pembebasan lahan } \\
\text { melibatkan pemilik } \\
\text { lahan, pemuka } \\
\text { masyarakat dan } \\
\text { pemerintah dalam } \\
\text { hal ini Balai Besar } \\
\text { Wilayah Sungai } \\
\text { Pompengan- } \\
\text { Jeneberang }\end{array}$ & $\begin{array}{l}\text { 1. Mampu mendukung } \\
\text { penataan prasarana } \\
\text { permukiman yang } \\
\text { menyediakan ruang } \\
\text { ekonomi sector } \\
\text { informal } \\
\text { - Jajanan kuliner } \\
\text { - Cendera mata } \\
\text { - Spot foto } \\
\text { - Atraksi seni yang } \\
\quad \text { bernilai jual } \\
\text { 2. Berkelanjutan dalam } \\
\text { pengembangan } \\
\text { kawasan permukiman } \\
\text { di tepian kanal berupa } \\
\text { rumah produksi } \\
\text { 3. Saran untuk } \\
\text { Pembebasan lahan }\end{array}$ \\
\hline
\end{tabular}

\subsection{Rencana Target Luaran Kegiatan Pengabdian Kepada Masyarakat}

Adapun target capaian luaran pada kegiatan pengabdian masyarakat ini adalah:

Produk Peta konsep arahan penataan prasarana Kawasan permukiman berbasis masyarakat.

Perbaikan tata nilai masyarakat; memupuk percaya diri masyarakat terhadap besarnya potensi rasa kebersamaan yang mampu menangani masalah perumahan (senibudaya, sosial, politik, keamanan, ketentraman, pendidikan, kesehatan)

\section{Implementasi Kegiatan}

Proses pelaksanaan kegiatan pengabdian akan melibatkan masyarakat setempat baik dalam proses perencanaan tapak, proses konstruksi sampai pada proses operasional dan pemeliharaan. Kepala Kelurahan Bontorannu menyambut baik pelaksanaan kegiatan ini dengan memberikan bukti kesediaan berpartisipasi pada kegiatan pengabdian ini. 
Kegiatan sosialisasi dilaksanakan di kawasan tepian Kanal Jongaya Kelurahan Bontorannu, Kecamatan Mariso. Hampir seluruh penduduk lokal dikawasan tersebut terlibat dalam kegiatan usaha yang berkaitan dengan kawasan permukiman tepian Kanal Jongaya. Kegiatan sosialisasi dihadiri lebih dari 50 masyarakat di Kelurahan Bontorannu tepatnya di kawasan tepian Kanal Jongaya. Sosialisasi dilaksanakan pada tanggal 25 Agustus 2019 pukul 10.00 WITA.

Kegiatan sosialisasi berisi penjelasan tentang pengarahan penataan permukiman yang lebih baik dan sehat khususnya di kawasan Kanal Jongaya. Masyarakat dapat memahami tentang pentingnya kebersihan lingkungan agar masyarakat tetap hidup sehat dan dapat meningkatkan kualitas permukiman. Sosialisasi ini juga dapat memberikan pemahaman bagi masyarakat setempat yang tinggal dekat permukiman tepian Kanal Jongaya tentang pentingnya penataan lingkungan untuk menciptakan kawasan yang layak huni, layak kunjungan dan layak investasi. Hal ini dapat mendukung masyarakat agar dapat menghasilkan suatu produk/barang dari hasil keterampilannya yang dapat dijual sehingga secara tidak langsung mampu meningkatkan ekonomi masyarakat.
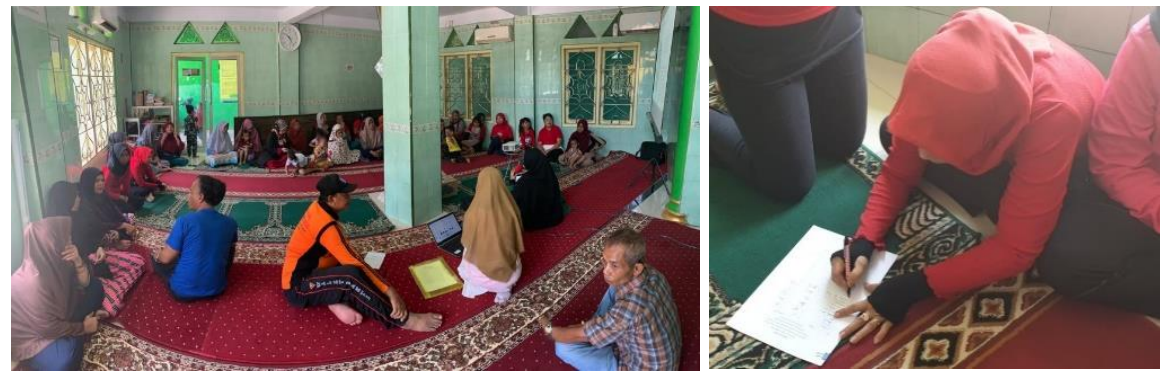

Gambar 2. Suasana Lokasi dan Registrasi Peserta
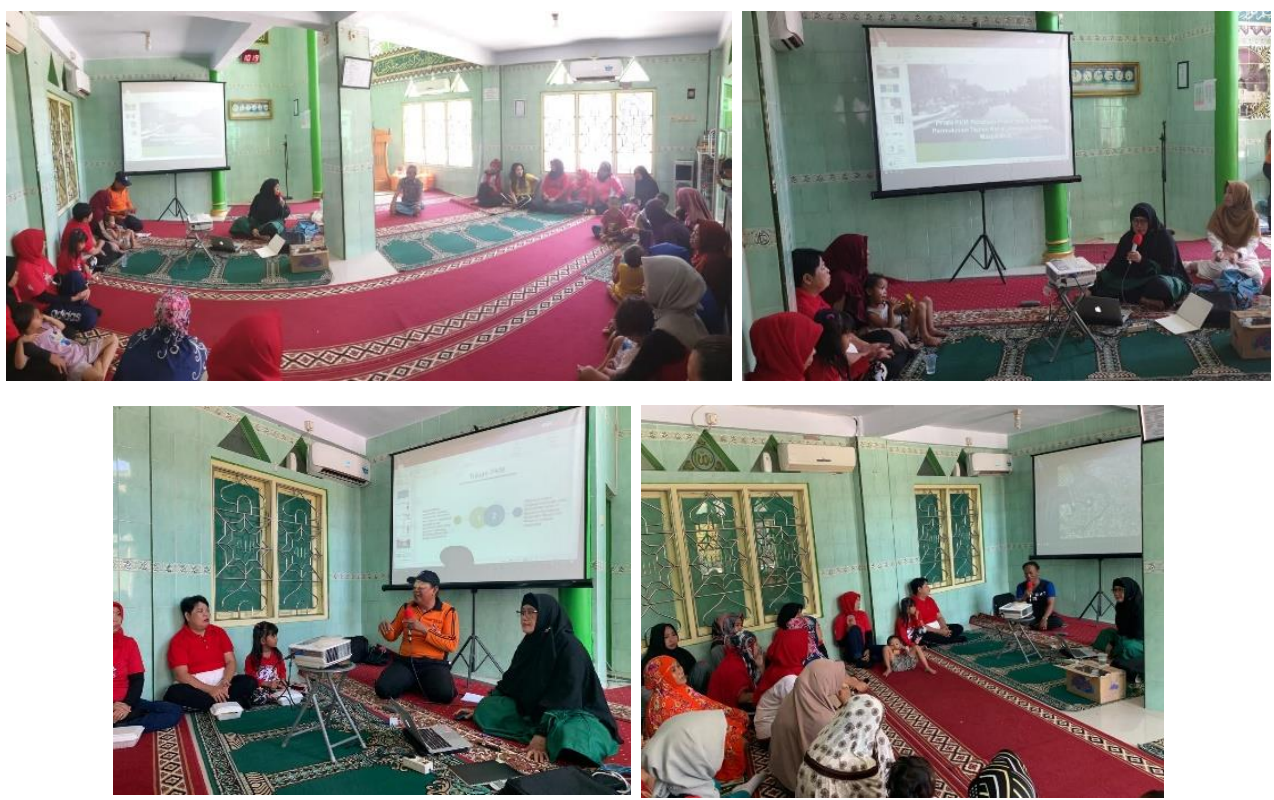

Gambar 3. Penyampaian Materi dan Umpan Balik 
| TEPAT Jurnal Teknologi Terapan untuk Pengabdian Masyarakat | Volume 3, Nomor 1, Tahun 2020

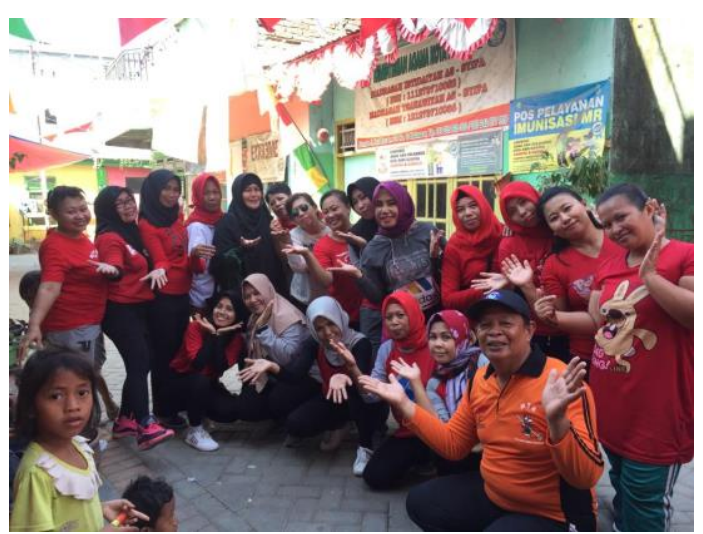

Gambar 4. Foto Bersama Peserta Sosialisasi
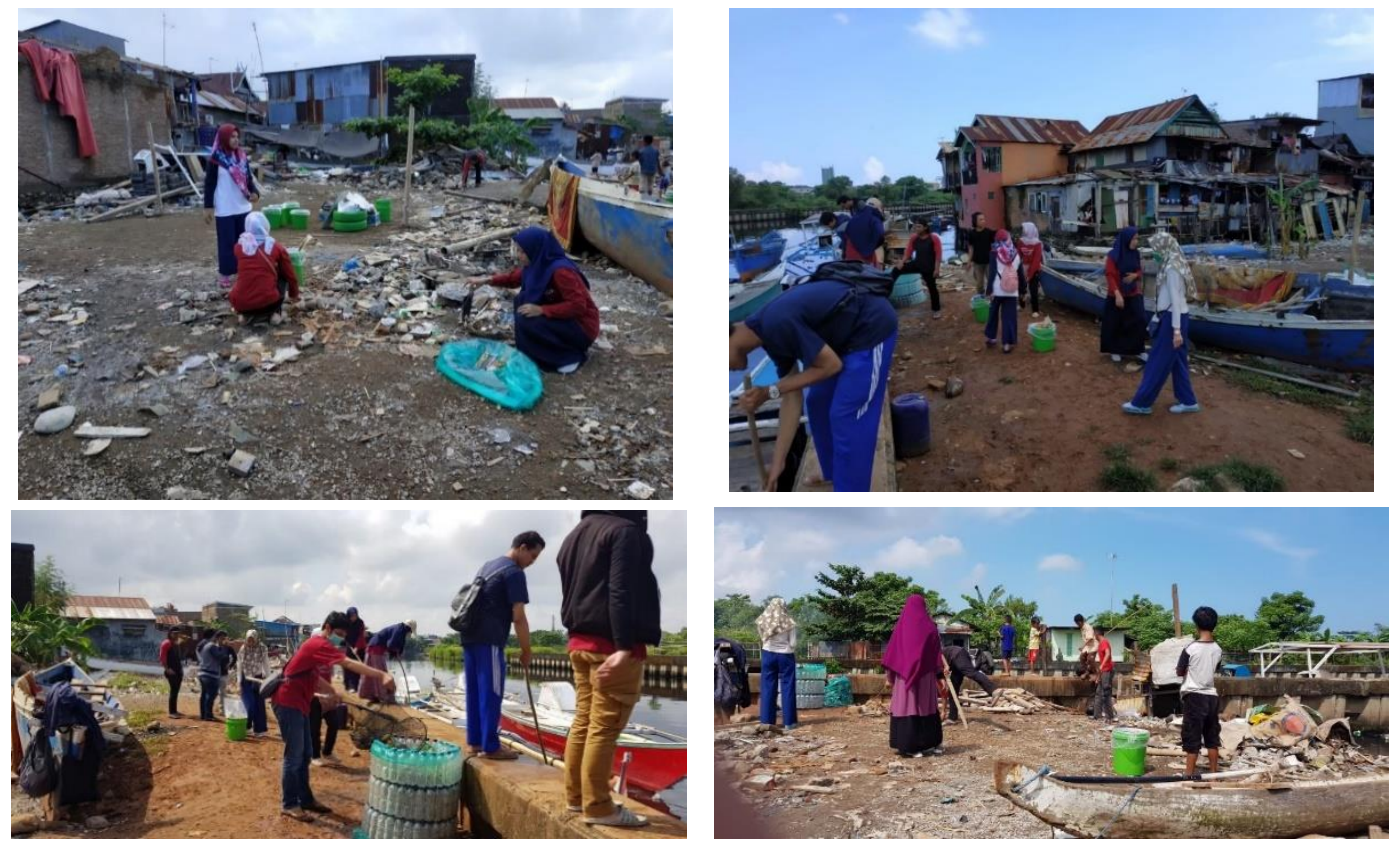

Gambar 5. Kegiatan gotong-royong membersihkan kanal bersama masyarakat dan mahasiswa
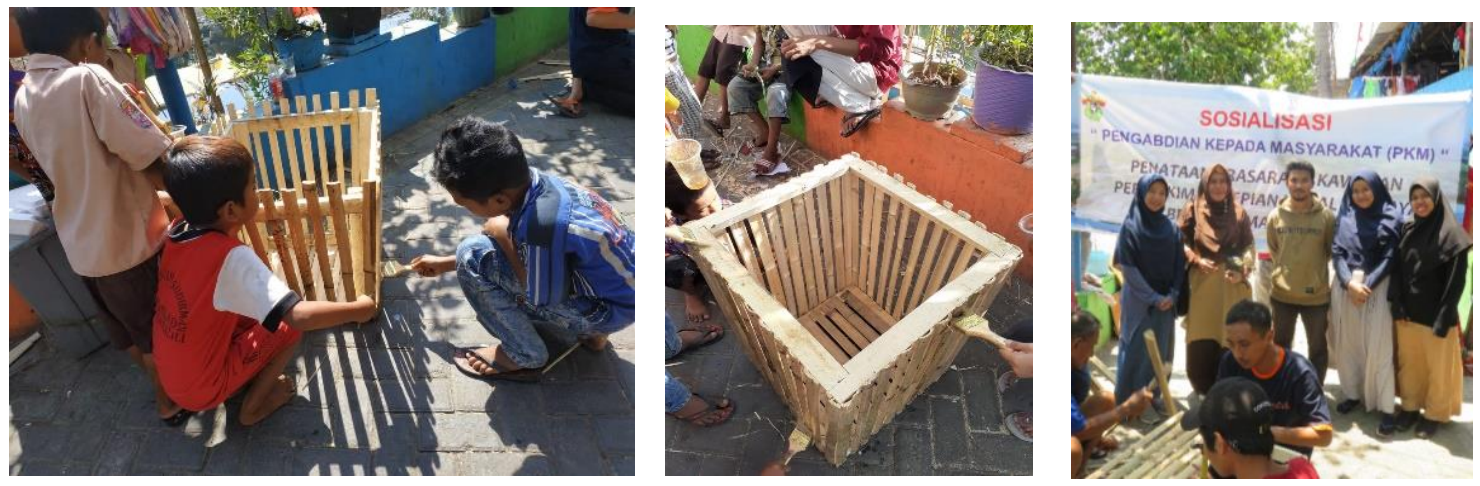

Gambar 6. Kegiatan membuat tempat sampah bersama masyarakat dan mahasiswa 


\section{Hasil dan Diskusi}

Sosialisasi tentang penataan prasarana kawasan permukiman ini telah dilaksanakan dan dipublikasikan kepada masyarakat tepian Kanal Jongaya secara langsung, serta telah mendapatkan umpan balik dari peserta sosialisasi mengenai saran dan keluhan bagaimana meningkatkan prasarana permukiman berbasis masyarakat. Arahan penataan yang direkomendasikan menyangkut proses menstimulus pemikiran masyarakat akan hal-hal utama yang harus dipenuhi dalam mengatasi kondisi permukiman yang ada yakni pengadaan lampu jalan, penambahan tempat sampah di setiap lorong dan tepi kanal, pembebasan lahan di RW 1, RW 2, RW 3, dan RW 4 untuk membuka akses jalan, disediakannya lahan parkir bagi wisatawan yang datang berkunjung, ajakan masyarakat untuk berjualan kuliner, cendramata, dan pembuatan spot foto untuk menarik kunjungan wisatawan sehingga dapat meningkatkan perekonomian masyarakat sekitar Kanal Jongaya.

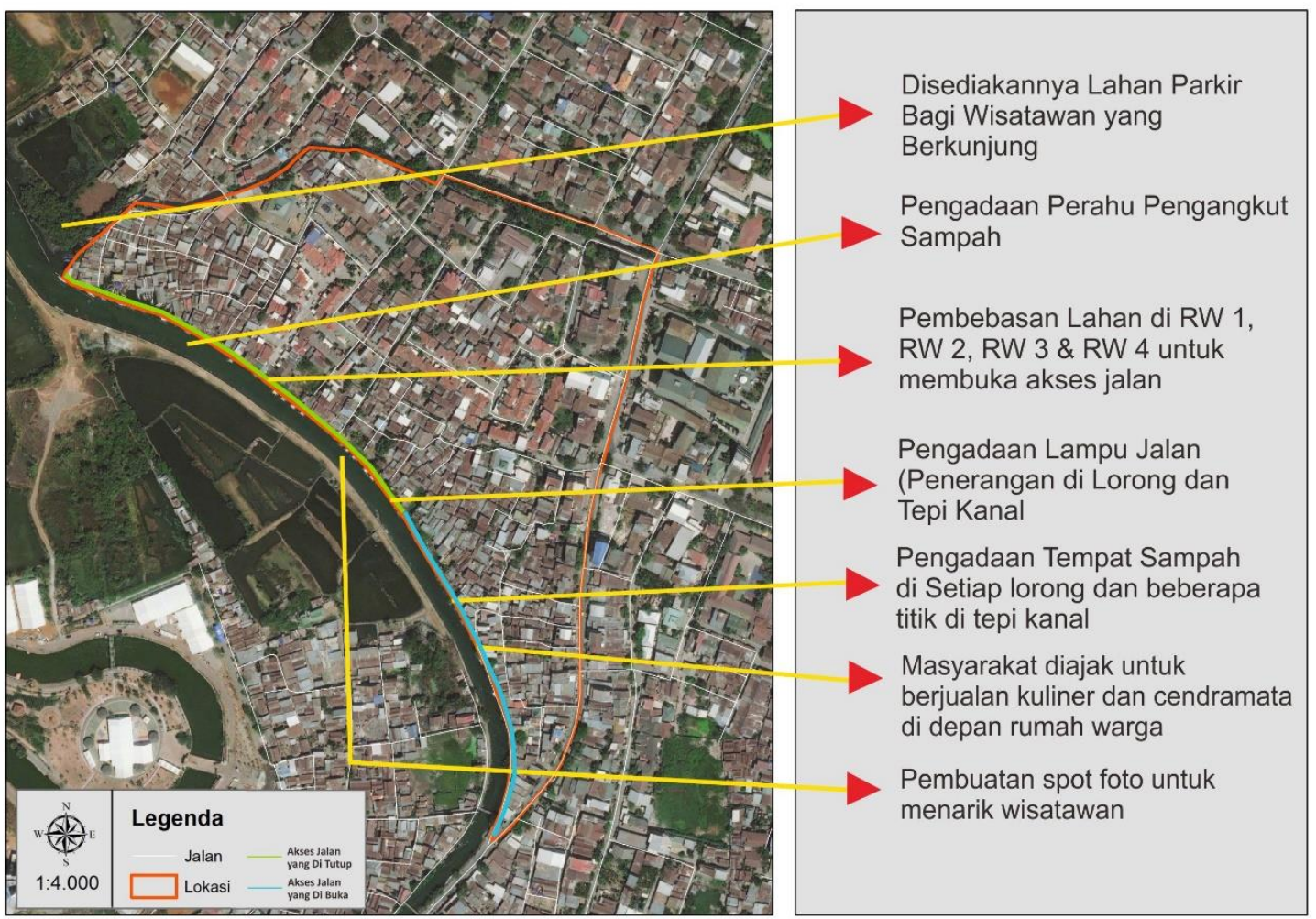

Gambar 7. Peta Arahan dan Peta Indikasi Konsep Perencanaan

\section{Kesimpulan}

Pendampingan membersihkan lingkungan serta pembuatan tempat sampah telah dilakukan bersama mahasiswa, seluruh masyarakat dan dosen dengan memupuk perasaan kebersamaan, sinergitas antara akademisi, pemerintah dan masyarakat.

Kegiatan sosialisasi dan pendampingan penataan mendukung proses peningkatan sumberdaya manusia dan lingkungan. Dalam hal ini menstimulus pemikiran masyarakat akan pentingnya 
kebersihan lingkungan, peningkatan kualitas lingkungan serta kesadaran dan pemahaman akan potensi kebersamaan mereka mampu mengatasi masalah kondisi permukiman

Agar berkelanjutan, diharapkan pemerintah daerah lebih tegas melakukan pengawasan pembangunan rumah terutama pada area sepanjang kanal serta pengawasan kebersihan lingkungan sekitar kanal.

Pemerintah Kota bekerjasama dengan Balai Besar Wilayah Sungai Pompengan-Jeneberang serta pemuka masyarakat dalam menangani pembebasan lahan sekitar kanal pada RW1,2,3 dan RW4 agar jalan dapat difungsikan sebagai sarana inspeksi kanal.

Untuk pemeliharaan kebersihan lingkungan yang akan mendukung kegiatan pariwisata yang akan berdampak pada peningkatan ekonomi masyarakat, pemerintah memotivasi swasta memberikan bantuan berupa program CSR dalam bentuk penyediaan perahu pengangkut sampah untuk mengatasi sampah kiriman melalui pasang surut air laut menuju kanal.

\section{Ucapan Terima Kasih}

Ucapan terima kasih kepada Ketua RW5, Ketua karang taruna, Kepala Kelurahan Bontorannu dan jajaran staf yang telah memfasilitasi pelaksanaan kegiatan ini serta turut serta mendorong keaktifan masyarakat dalam kegiatan ini. Terima kasih atas kerjasama antar tim peneliti dengan koordinator setempat yakni Ketua RT di Kelurahan Bontorannu Tepian Kanal Jongaya serta mahasiswa.

\section{Daftar Pustaka}

Permen PU No 40 Tahun 2007 tentang Pedoman Perencanaan Tata Ruang Kawasan Reklamasi Pantai.

Peraturan Menteri Pekerjaan Umum Nomor 63 Tahun 1993 tentang Garis Sempadan Sungai, Daerah Manfaat Sungai, Daerah Penguasaan Sungai dan Bekas Sungai.

Peraturan Menteri Pekerjaan Umum Nomor : 03/Prt/M/2014 tentang Pedoman Penyediaan \& Pemanfaatan Prasarana dan Sarana Ruang Pejalan Kaki di Perkotaan Kementrian Pekerjaan Umum.

RTRW Kota Makassar 2015-2034.

Syafri, 2007. "Sikap Masyarakat Terhadap Rencana Penataan Kawasan Sungai Siak Kota Pekanbaru". Tesis, tidak diterbitkan, Program Magister Teknik Perencanaan Wilayah dan Kota, Semarang: Universitas Diponegoro. 